\title{
Recent Advances in Direct and Indirect Methods of Fine Particle Characterization
}

\author{
Yvonne L Fornishi ${ }^{1}$, Raafat Fahmy ${ }^{2}$ and Hany F Sobhi ${ }^{*}$ \\ ${ }^{1}$ Department of Natural Sciences, Coppin Center for Organic Synthesis, Coppin State University, Baltimore, Maryland 21216, USA \\ ${ }^{2}$ U.S. Food and Drug Administration, Silver Spring, Maryland 20993, USA
}

"Corresponding author: Hany F Sobhi, Department of Natural Sciences, Coppin Center for Organic Synthesis, Coppin State University, Baltimore, Maryland 21216, USA, E-mail: hsobhi@coppin.edu

Received: 06 Mar, 2018 | Accepted: 30 Mar, 2018 | Published: 05 Apr, 2018

Citation: Fornishi YL, Fahmy R, Sobhi HF (2018) Recent Advances in Direct and Indirect Methods of Fine Particle Characterization. J Pharm Anal Insights 2(1): dx.doi.org/10.16966/2471-8122.116

Copyright: (C) 2018 Fornishi YL, et al. This is an open-access article distributed under the terms of the Creative Commons Attribution License, which permits unrestricted use, distribution, and reproduction in any medium, provided the original author and source are credited.

\section{Abstract}

This review includes the most recent advances in fine particle characterization based on direct and indirect methods. Fine particles characterized with the size of 2.5 micrometer are defined as particles that have reduced visibility to the human eye, and causes the air to appear hazy when levels are elevated. Within this article, pharmaceutical drug formulation of fine particle size and distribution is well defined as described by the United States Pharmacopeia (USP). This review highlights the direct methods, which include the following: sedimentation rate, analytical sieve fractionation studies, and light microscopy; as well as indirect methods of characterization, which includes laser diffraction analysis, method validation and permeability procedures. Furthermore, statistical analysis in particle size is expressed within and it is used to summarize large amounts of collected data into a form that could be useable and understandable while losing as little information as possible about the original investigated population.

Keywords: Measurements of the particle size; Particle size distribution (PSD); Particle shape; Characterization of particles; Light microscopy; Laser diffraction analysis; Particle size specifications; Solubility; permeability; Sedimentation of fine particles

\section{Appendix}

APIs-Active Pharmaceutical Ingredients; BCSBiopharmaceutical Classification System; COPD-Chronic Obstructive Pulmonary Disease; DNA- Deoxyribonucleic
Acid; GI-Gastrointestinal Track; HPH-High Pressure Homogenization; ICH-International Conference on Harmonization; LED-Light-Emitting Diode; PS-Particle Size; PSD-Particle Size Distribution; PGP-P-Glycoprotein; USPUnited States Pharmacopeia

\section{Introduction}

Fine particle or matter is regard as particles that have reduced visibility to the human eye and causes the air to appear hazy when levels are elevated. They have a particle size of 2.5 micrometer and are particularly high outdoors compared to indoors $[1,2]$. They are a breakdown of majority solids compared to liquids or gases. Characterization of these particles is extremely useful and important when making determinations in the processes of mixing, extruding and pneumatic handling of powered materials. Also, the process of particle characterization is composed of the size of the particles and its various modes of distribution.

Recently, foods are processed from their solid forms to fine particles for consumer consumption. Thus, fine particles are highly dependent on the particle size and size distribution. Other properties that are equally dependent on the abovementioned characteristics include particle flow ability, compressibility and particle density [3]. Moreover, identifying the characteristics of fine particles makes it feasible for industries such as food, pharmaceutical and other industries that deal with fine particles to be able to process and market their products for ease of consumer consumption or usage.

\section{Importance of particle size in the pharmaceutical industry}

Identifying the importance of particle sizes is imperative because other properties of the particle may or may not be affected. Per an article written by Fairhurst and Weiner [4] where they eluded that particle characterization is based on the measurements of the particle size (PS), particle size distribution (PSD), sometimes particle shape, and morphology. Also, they expressed that PSD affects particle properties such as 
suspension. Within the pharmaceutical trade, the PS and PSD of active pharmaceutical ingredients (APIs) are affected during the suspension phase thus having an implication on the stability and sustainability of the compound. The direct repercussion of PS and PSD are observed in the behavior characteristics of these fine particles and they include bioavailability (represented by $f$ ) of the compound, toxicity as well as the dissolution rate [5]. The PSDs of both drug substances and excipients can affect drug product manufacturability (e.g., flow ability, blend uniformity, compatibility, etc.), which, ultimately can impact safety, efficacy, and quality of the drug product. Therefore, the impact of particle size distribution of powders on drug product manufacturability and performance should be evaluated at different pharmaceutical development phases for each specific drug application [6]. Additionally, the appropriate particle size specification for each drug product should be established for control of drug product quality as well as ensuring manufacturing consistency.

For solid oral dosage forms, particle size plays an important role during the manufacturing process and the quality of the finished drug product. For example, granulation and coating are related to particle size enlargement, while milling is related to particle size reduction. Screening and sieving are related to separation of particles with different sizes, which may influence the mixing process and affect the blend uniformity. Therefore, understanding the impact of particle sizes and shape of powders on manufacturing processes is critical. For raw or in-process materials, the effects of their particle sizes on manufacturing processes (e.g., mixing, granulation, milling, blending, coating, etc.) are significant, thus controlling PSDs of these pharmaceutical powders is necessary to ensure manufacturing consistency. Moreover, knowing the importance of PS and PSD of a fine particle is critical to the composition of the entire compound as well as the characteristics that make up the compound. Within the pharmaceutical industry, fine particles are important because they aid in size distribution, solubility and dissolution of compounds [6]. Additionally, they aid in the delivery mode of the agent such as parenteral, oral, topical and inhalation. The higher the solubility (predominantly water soluble), the higher the possibility of it being administered orally, parentally or via inhalation. The less soluble (predominantly lip soluble) an agent is, the higher chance it will be administered topically due to increase absorption into the skin.

\section{Establishing particle size specifications}

It is important to understand what information should be included in particle size specifications so it could meet regulatory requirements. Per International Council for Harmonization (ICH) guideline Q6A, a specification is defined as a list of tests, references to analytical procedures, and appropriate acceptance criteria, which are numerical limits, ranges, or other criteria for the tests described [7]. Since sieving and laser diffraction are the most common methods used in drug applications, the discussion will mainly focus on these two particle sizing methods.

\section{Analytical procedure}

With regard to the analytical procedure, United States Pharmacopeia (USP) general chapters <786> and <429> have provided useful information and requirements for the sieving and the laser diffraction methods respectively. In summary, a particle size specification is required if the particle size of the drug substance is critical to drug product performance (i.e., dissolution, solubility, bioavailability, content uniformity, stability, or product appearance) or drug product manufacturability (i.e. processability).

\section{Characterization Methods}

For the drug substance, the ICH guideline Q6A provides guidance (decision tree \#3) on when a particle size specification should be considered [7]. There are a variety of techniques that are used to estimate the size of particles and these are classified as either direct or indirect methods. Some direct methods of particle size estimation includes optical and image analysis while some indirect methods of particle size estimation includes sedimentation, sieving, fluid classification and scanning.

\section{Direct methods}

This is a descriptive technique that is used to estimate the size distribution of fine particles. It is often denoted as a definite method because the particles are seen and measured directly [3]. Direct methods towards fine particle characterization includes the sedimentation methods, analytical sieve fractionation studies and microscopy.

Sedimentation rate: This process is also known as the settling of a solid phase which occurs in a majority of processes involving suspensions [7]. This is represented by the use of Stokes Law which involves parameters such as diameter (D), gravitational constant $(g)$, effective solid density $\left(\rho_{s}\right)$, liquid density $\left(\rho_{1}\right)$, liquid viscosity $(n)$ and settling velocity (height/ time) $(\mathrm{U}=\mathrm{H} / \mathrm{t})[8]$.

Analytical sieve fractionation studies: This includes the fractionation of powders which is known as a popular technique for characterizing and classifying powders. It is a method of choice for determining the size distribution of granular powders such as APIs, excipients and tablet granulations.

Performing sieving analysis of pharmaceutical materials is fully described in the USP General Test $<786>$. The USP identifies two methods of sieving: dry-sieving (denoted as Method I) and wet-sieving (denoted as Method II). The inaccuracies and uncertainties of characterization by sieve fractionation arises from the experimental problems of weighing the sieve residues and from the non-ideal nature of the woven or wire mesh of the sieve surface.

Analytical sieving using wire mesh provides a two dimensional estimate of size because the smallest dimension of each particle, dictates its ability to go through a given sieve 
opening. The standard sieve opening is known to measure about 50 micrometer [9]. For the sieving method, the following parameters are recommended for validation of robustness: (1) sample mass, (2) tap rate, (3) rotation rate, and (4) agitation time.

Light microscopy: These are widely found in pharmaceutical laboratories; however, they are seldom used to their full potential due to lack of understanding of the different types of illuminations available and proper sample preparation techniques. The types of illumination commonly available include: brightfield, darkfield, oblique, polarized light, phase contrast and differential interference contrast.

Brightfield illumination: This is a form of light microscopy where contrast is generated from changes in light absorption, refractive index or color [10]. This occurs when surfaces which are perpendicular to the axis of the objective appear bright. It is the first form and is most widely used. However it may be the least appropriate for fine particles characterization because if the fine particle is a transparent crystal, then the particle may appear as a nearly featureless silhouette.

Darkfield illumination: As a form of light microscopy, the light rays are directed around the objective lenses from a $360^{\circ}$ angle as opposed to through it. The scattered light is caused by optical discontinuities and the light is reflected by any surface irregularities at specific angles that enter the object [10]. The most minute deviation from an absolutely plane mirror like surface will show up bright on a black background. This type of illumination is therefore useful in examining both external and internal topography of a particle.

Oblique illumination: This type of illumination occurs when the rays of light are decentered [10]. This causes them to strike the reflecting surface from one direction at an angle. This type of illumination is useful in viewing the surface topography in large crystals and granules as it creates shadows on uneven surfaces that results in three dimensional reliefs. Increasingly, microscopists working at low magnification have turned to fiber optic and light-emitting diode (LED) illuminators to provide oblique illumination.

Polarized light illumination: This is an imaging technique based on light scattering. It performs rapid two to three dimensional imaging of transparent and translucent samples with micrometer scale resolution. It also provides image contrast based on the polarization state of backscattered light and has been applied in many biomedical fields as well as in non-medical fields [11]. Also, it has many valuable properties that merit understanding. Most illumination sources for microscopy emit beam of heterogeneous light in which the waves vibrate in all directions perpendicular to the axis of propagation. Polarizing media presents optical slits that act somewhat like venetian blinds. They pass a portion of the light plane polarized according to the orientation of the slits. A polarized element typically transmits about $32 \%$ of the incident light as plane-polarized light.

Phase contrast illumination: This allows one to view live organisms, and often, primarily in eukaryotes, internal structures without staining. Staining often kills, and can alter specimens. It is an example of the white light technique [12].

Differential interference contrast illumination: This is a microscopy technique that visualizes a specimen of weak contrast by converting the field gradient of a light into intensity variation. It has served as a label-free tool to image biological specimens. Light-shearing prisms and polarized light have been used to exaggerate minute differences in specimen thickness gradients and refractive index [13].

\section{Indirect methods}

This is also denoted as a descriptive technique which is used to estimate the distribution size of fine particles. It includes the most popular indirect methods of fine particle characterization. This is known as laser diffraction analysis, method validation and permeability procedures.

Laser diffraction analysis: This provides an indirect measurement of size of spherical particles found on the principle that particles of a known size tend to diffract light via a given angle that increases logarithmically with decreased size [14]. Moreover, the fine particle sample is deduced from the analysis of a diffraction pattern, which is evaluated using a set of complex equations. For the laser diffraction method, the following parameters are recommended for validation of robustness: (1) measurement stability, (2) refractive index, (3) dispersion pressure (for the dry measurement), and (4) sample concentration, sonication, and stir rate (for the wet measurement). It should show the reliability of an analysis with respect to deliberate variations in method parameters. A study should also be included in the method validation report to demonstrate that the sampling and sample dispersion strategies described in the analytical procedure are reliable and reproducible. Finally, it is recommended to use the imaging analysis as a complimentary tool to assess the particle shape, size range, and the suitability of the selected sieving or laser diffraction methods.

Method validation: Validation of the particle sizing method usually involves evaluation of precision (repeatability and intermediate precision) and robustness. Other ICH defined validation parameters, such as specificity, linearity, range, accuracy, detection limit, and quantitation limit are not normally required for validation of the particle sizing method. For validation of precision, repeatability refers to the use of the analytical procedure within a laboratory over a short period of time using the same analyst with the same equipment. Intermediate precision (also known as ruggedness) is a measure of variation within a laboratory, as on different days, or with different analysts or equipment within the same laboratory [4]. If the particle sizing method will be transferred to other laboratories, evaluation of reproducibility which includes the use of the analytical procedure in different laboratories is required.

Robustness of an analytical procedure is a measure of its capacity to remain unaffected by small, but deliberate 
variations in method parameters and provides an indication of its reliability during normal usage [4]. Evaluation of robustness should be considered during the development of the particle sizing method. Once the optimal method parameters are determined, robustness can then be evaluated by deliberating small variations of these parameters.

Permeability procedures: This is defined as the formation of powders independent of the fluid [15]. Also, it allows for fluid to slowly move through the powder or fine particles with ease. When two or more fluids are present, it reduces the flow of permeability for each of the fluid into the fine particle. Permeability is dependent on particle size. The bigger the size of the particle, the less permeable the fluid will be and the smaller and finer the particle size is, the more permeable the fluid will be.

\section{The operational integrity of a fine particle}

When developing a test sample preparation and characterization procedure for studying fine particles, it must be determined that the treatment of fine particles does change their structure, either by fracturing the structure or by causing flocculation.

Fracturing the structure of fine particles: The main factor influencing the change in the fracture behavior of fine particles is not the size of the structural fragments but the size and density distribution the particles. This means that the microstructure fragment size is not a factor that causes a qualitative change in the fracture behavior of the fine particles [16].

Flocculation: Simple magnetic separation for ultrafine disseminated lean elements has resulted in low performance, as the fine sizes and aggregation of ground mineral particles have caused inefficient recovery of the ultrafine or fine particles [5]. For example, a common technique for dispersing the drug in a liquid vehicle prior to laser diffraction analysis is to agitate a suspension of the particles in an ultrasonic cleaning bath. To casual observers, the ultrasonic agitation appears to be in a relatively low energy dispersal procedure. However, the suspension of fine particles is actually being subjected to impact forces in the order of tons per square centimeter. The magnitude of the impact can be demonstrated by placing a sheet of household aluminum foil in an ultrasonic water bath for a minute or two. When a bright light is viewed through the foil, it may be seen that the foil is riddled with tiny punctures. The foil is punctured by microscopic water droplets that are thrown against the foil during the collapse of the vacuum filled cavities formed by the ultrasonic waves.

As a result, it is easy to see how ultrasound can result in the breakdown of the agglomerates into the constituent units that are much smaller than the agglomerate. On the same note, if the drug crystals are friable, mere seconds of exposure to an ultrasonic water bath can dramatically fragment the crystals. Even the energy of vibration during mesh analysis of fracture drug crystals has been observed. Thus the unintended alteration of the sample will cause problems in relating particle size information to the behavior of the powder. Therefore, before routinely employing any preparatory techniques, the effects of test sample preparation should be assessed by viewing the fine particles before and after preparation with the aid of a light microscope.

\section{Properties of fine particles}

Structure: The structure of fine particles is dependant on the particle size due to the effect of the cohesiveness of van der Waals forces [17]. As particle size decreases, so does the inter-particle forces such as van der Waals forces become more dominant. This forces making the structure of the fine particles to change and become more uniform.

Size distribution: This is very important to products and industries especially pharmaceutical industries. The relevance of size distribution towards this industry is that the stability, aesthetics, rate of absorption and total bioavailability are all affected by the size and distribution of the particle. Particle size has a strong role in determining the differential sinking rates of various particle types [18]. The finer the particle, the easier it is to be stable in solutions and vice versa.

Surface Properties: These are important to fine particles because they tend to adhere to surfaces that are rough, hard or wet [19]. The adhesion of fine particles is indeed a complicated process thus the shape, size and hardness of the fine particle will determine what kind of surface will be fit for it. For example, comparing between porcelain and glass, fine particles will be easily be absorbed in the porcelain material compared to the glass material. This is due to the fact that the glass material has a lower surface finish and its adhesive property towards particles is lower than that of the porcelain material.

\section{Characterization of particles}

Particle characterization is classified into two categories: physical and chemical complexities. With the physical complexities of fine particles, there are characteristics that make that up. These include: particle size, morphology (how the particles are formed) of the particle and crystallinity of the particle. Furthermore, the chemical complexities of particles are composed of the following: the elemental composition of the particle, chemical form, chemical satisfaction and isotopic ratio [20].

\section{Physical complexities}

Particle size: This is seen as the most important physical property of particle primarily fine particles. This property is carried out across a multitude of industries and it is a critical parameter in the measurement of many products [21]. It has a direct influence on the following drug properties: reactivity or dissolution rate such as tablets, capsules or catalyst, stability in suspension such as sedimentation rate, feel and texture such as ingredients and excipients, modes and efficacy of delivery such as via inhalation, topically, parentally or orally, appearance such 
as coatings, viscosity such as agents used as nasal sprays, flow ability and handling, and porosity and density of compound. Particle size reduction can be achieved by a range of different means; some of which include the following: micronization and nano-suspension.

Micronization: This is a simple technique that involves the transfer of coarse powder to an ultrafine powder with a mean particle size range of 2-5 $\mathrm{mm}$. Most often, only a very small fraction of the particles lie below the $1 \mathrm{~mm}$ size range [22]. Micronization of particles is performed by using the milling techniques which includes jet mill, ball mill and high pressure homogenization $(\mathrm{HPH})$. Examples for this type of particle size reduction will be elaborated under the effects of particle size on solubility. Table 1 will show the advantages and disadvantages of using micronization in the reduction of particle size [23].

Nano-suspension: This is a sub-micron colloidal dispersion of pure particles of drug that are stabilized by the use of surfactants. Some techniques involved with nano-suspension include wet milling and homogenization. This approach had been used to increase the solubility of several drugs some of which include: paclitaxel, tarazepide, amphotericin B, buparvaquone and atorvaquone. Table 2 will illustrate some advantages and disadvantages of using nano-suspension as a means to reduce particle size [24,25].

\section{Morphology - Particle Shape}

Just like the particle size, the morphology of a particle is equally as important because it could affect a multitude of properties during the procession of the compound. This has become an area of interest within many manufacturing industries. Some of the areas in which the particle shape could impact include: pharmaceutical activities such as reactivity and solubility, food ingredients such as texture and feel and drug delivery systems such as flow ability and handling. Table 1 lists some particle shapes used in pharmaceutical drug formulations and their definitions according to USP. With the various particle shapes, they have as well different effects on drug flow ability. Such effects based on particle type are better elaborated below on Tables 3 and 4 (Figure 1).

\section{Particle Shape Factors}

Characterization of a particle shape is often seen as complicated but the goal of a shape factor is to define the shape of an irregular particle. Thus a mathematical model is used to identify how spherical or square a particle is and how different an irregular particle is from a commonly identifiable shape [30]. The shape factor is often seen to be independent of the particle size and flow ability. Although there are a multitude of pharmaceutical particles that to the naked eye are the same size and weigh the same, they often have a wide distribution of shapes, hence the shape factor [28]. Some commonly used and
Table 1: Advantages and Disadvantages of Micronization [23]

\begin{tabular}{|l|l|}
\multicolumn{1}{|c|}{ Advantages } & \multicolumn{1}{c|}{ Disadvantages } \\
\hline $\begin{array}{l}\text { Used to increase surface } \\
\text { area for dissolution }\end{array}$ & $\begin{array}{l}\text { Does not increase equilibrium } \\
\text { solubility }\end{array}$ \\
\hline $\begin{array}{l}\text { Increases dissolution rate of } \\
\text { drugs via } \\
\text { increased surface area }\end{array}$ & $\begin{array}{l}\text { Not suitable for drugs having a high } \\
\text { dose number due to it not changing } \\
\text { the saturation solubility of the drugs }\end{array}$ \\
\hline
\end{tabular}

Table 2: Advantages and Disadvantages of Nano-suspension [24,26,27]

\begin{tabular}{|l|l|}
\multicolumn{1}{|c|}{ Advantages } & \multicolumn{1}{c|}{ Disadvantages } \\
\hline $\begin{array}{l}\text { Increases dissolution } \\
\text { rate }\end{array}$ & $\begin{array}{l}\text { Conversion of high-energy polymorph to } \\
\text { low- energy crystalline forms }\end{array}$ \\
\hline $\begin{array}{l}\text { Causes and increases } \\
\text { surface area }\end{array}$ & $\begin{array}{l}\text { Crystalline forms are most often not } \\
\text { therapeutically active }\end{array}$ \\
\hline
\end{tabular}

Table 3: Shape Characterization Specified by USP [28]

\begin{tabular}{|l|l|}
$\begin{array}{c}\text { Particle } \\
\text { Shape }\end{array}$ & \multicolumn{1}{c|}{ Definitions } \\
\hline Acicular & Slender, needle-like particle of similar width and thickness \\
\hline Columnar & $\begin{array}{l}\text { Long, thin particle with a width and thickness that are } \\
\text { greater than those of an acicular particle }\end{array}$ \\
\hline Flake & Thin flat particle of similar length and width \\
\hline Plate & $\begin{array}{l}\text { Flat particles of similar length and width, but with greater } \\
\text { thickness than flakes }\end{array}$ \\
\hline Lath & Long, thin and blade-like particles \\
\hline Equant & $\begin{array}{l}\text { Particles of similar length, width and thickness. These } \\
\text { include both cubical and spherical }\end{array}$ \\
\hline
\end{tabular}

Table 4: Effects of particle shapes and flow [29]

\begin{tabular}{|l|l|l|}
\hline $\begin{array}{l}\text { Particle } \\
\text { Type }\end{array}$ & \multicolumn{1}{|c|}{ Definitions } & \multicolumn{1}{c|}{ Effects on flow } \\
\hline $\begin{array}{l}\text { Fibrous } \\
\text { particles }\end{array}$ & $\begin{array}{l}\text { Regularly or } \\
\text { irregularly thread-like }\end{array}$ & $\begin{array}{l}\text { Shows poor flow ability and } \\
\text { bridges easily }\end{array}$ \\
\hline $\begin{array}{l}\text { Flaky } \\
\text { particles }\end{array}$ & Plate-like & $\begin{array}{l}\text { Often produces greater flow } \\
\text { interlocking particles, but less flow } \\
\text { ability than the spherical, oblong } \\
\text { shaped and equidimensional } \\
\text { particles. They may also cause } \\
\text { bridging }\end{array}$ \\
\hline $\begin{array}{l}\text { Spherical } \\
\text { particles }\end{array}$ & Global shaped & $\begin{array}{l}\text { These often produce good flow } \\
\text { ability }\end{array}$ \\
\hline $\begin{array}{l}\text { Irregular } \\
\text { particles }\end{array}$ & these lack symmetry & $\begin{array}{l}\text { These often produce poor flow } \\
\text { ability and causes bridging }\end{array}$ \\
\hline $\begin{array}{l}\text { Granular } \\
\text { particles }\end{array}$ & $\begin{array}{l}\text { These have } \\
\text { approximately and } \\
\text { equidimensional } \\
\text { irregular shape }\end{array}$ & $\begin{array}{l}\text { They have less flow ability than the } \\
\text { spherical and oblong shape }\end{array}$ \\
\hline $\begin{array}{l}\text { Oblong } \\
\text { particles }\end{array}$ & $\begin{array}{l}\text { They have smooth } \\
\text { edges }\end{array}$ & $\begin{array}{l}\text { They often produce good flow } \\
\text { ability }\end{array}$ \\
\hline
\end{tabular}

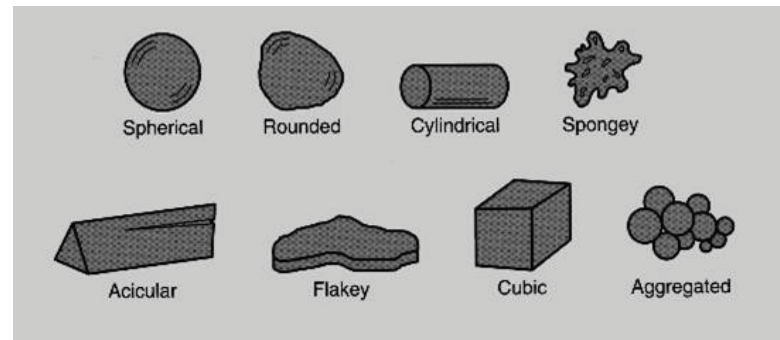

Figure 1: Some of the different particle shapes [29] 
cited shape factors in the pharmaceutical industry include, but are not limited to:

\section{Wadell's true sphericity and circularity}

This is the oldest particle shape factor used in the pharmaceutical industry. True sphericity is defined by the proximity of irregular particle measured to a perfect sphere as well as the relationship between the irregular particles to the perfect sphere [30].

\section{Correction factor}

It has been expressed in several writings that the correction factor could be expresses in terms of a volume factor and a surface factor with a distinct statistical diameter of an irregular particle. The following could be expressed in the formula below:

$$
V=\left\{\left(\pi d_{v}^{3}\right) \div 6\right\}=\alpha_{v} d^{3}
$$

and

$$
S=\pi d_{s}^{2}=\alpha_{s} d^{2}
$$

Additionally, the volume and surface factors could be also used in the specific equation (Sw) when Sw is of interest [30].

\section{Dallavalle's shape factor}

This factor can be useful for a log normal distribution because the shape of the size-frequency also known as density distribution curve and can be taken into account when combining Martin's correction factor with the Hatch-Choate equation [30].

\section{Fractal dimension}

The fractal dimension shows the degree of irregularity or ruggedness of the particle. Also, it refers to a rough geometric shape that is composed of many smaller copies that have the same shape but different sizes. Despite its uniqueness, it did not gain popularity within the pharmaceutical industry because it cannot clearly distinguish between spherical, polygonal, or unorganized particles [31].

\section{One plane critical stability}

This is a two-dimensional shape factor that characterizes the roundness of a particle. It is identified as the minimum angle between a horizontal plane and the surface where the particle is lying upon. This factor is more applicable to spherical shapes as opposed to any other. However, it only detects minor differences in roundness and requires individual measurements of the particles involved using a specialized computer system [30].

\section{Crystallinity}

Crystallinity of a particle, particularly fine particles have a huge influence on the diffusion rate of the particle, its hardness, its density as well as its transparency [32]. The more crystalline a particle or drug substance is, the high its diffusion rate thus increasing the bioavailability of the particle or drug substance. Concurrently, if the crystallinity of a particle is decreased, then the lower its diffusion rate will be thus decreasing the bioavailability of the particle or drug substance. Crystallinity of a particle can be decreased by adding the following: presence of additives such as drug excipients (color, flavoring, etc.) which are periodically added to drugs to make them more appealing for patients to consume.

\section{Enhancing Solubility}

Drug solubility defined as the maximum concentration of the drug solute dissolves in the solvent under specific conditions such as temperature, $\mathrm{pH}$ and pressure. This may be expressed as parts, percentage, molarity, molality, volume fraction, and mole. Additionally, the solubility of a drug is described in various descriptive terms which is based on the amount of drug dissolved in solvent fraction [32]. Table 5 outlines the various descriptive terms of solubility as well as the approximate volume of solvent in milliliters per gram of solute.

\section{Enhancing Permeability}

Permeability of drugs is essential in terms of it reaching systemic absorption. For drugs with low permeability such as metformin and aliskiren, they are formulated with higher doses so as to compensate their low bioavailability. The framework used for classifying APIs is based on solubility and permeability, is called the Biopharmaceutical Classification System (BCS). APIs with low permeability are BCS classes III and IV while those with high permeability are BCS classes I and II. Some common approaches to enhancing bioavailability of drugs with low permeability includes: intestinal membrane permeation enhancers, p-glycoprotein (PGP) inhibitors, prodrugs, lipid or surfactant vehicles, and iron paring complexation [34].

\section{Need for solubility and permeability}

There are various factors that can limit drug absorption in the gastrointestinal (GI) tract some of which include solubility and permeability of APIs. Once an API is administered orally, it has to dissolve in the gastric or intestinal fluid before it can easily permeate the membranes of the GI tract thus reaching systemic circulation. The BCS lends to identify APIs in classes I through IV based on their level of solubility and permeability $[34,35]$. APIs with high solubility and permeability have an increase bioavailability in hydrophilic environments. Conversely, those with low solubility and permeability, have increased bioavailability in lipophilic environments. Table 6

Table 5: Descriptive Terms of Drug Solubility [33]

\begin{tabular}{|l|l|}
\multicolumn{1}{|c|}{ Descriptive Terms } & \multicolumn{1}{|c|}{$\begin{array}{c}\text { Approximate volume of solvent in } \\
\text { milliliters per gram of solute }\end{array}$} \\
\hline Very Soluble & $\leq 1$ \\
\hline Freely Soluble & $\leq 1-10$ \\
\hline Soluble & $\leq 10-30$ \\
\hline Sparingly Soluble & $\leq 30-100$ \\
\hline Slightly Soluble & $\leq 100-1000$ \\
\hline Very Slightly Soluble & $\leq 1000-10,000$ \\
\hline Insoluble & $\geq 10,000$ \\
\hline
\end{tabular}


Table 6: Biopharmaceutical Classification System (BCS) $[36,37]$

\begin{tabular}{|c|c|c|c|}
\hline $\begin{array}{l}\text { BCS } \\
\text { Class }\end{array}$ & $\begin{array}{l}\text { Solubilityl } \\
\text { Permeability } \\
\text { Status }\end{array}$ & Problems & Examples \\
\hline I & $\begin{array}{l}\text { High Solubility } \\
\text { High } \\
\text { Permeability }\end{array}$ & $\begin{array}{l}\text { Enzymatic } \\
\text { degradation, gut } \\
\text { wall efflux }\end{array}$ & $\begin{array}{l}\text { Beta Blockers such as } \\
\text { Propranolol, Metoprolol }\end{array}$ \\
\hline II & $\begin{array}{l}\text { Low Solubility } \\
\text { High } \\
\text { Permeability }\end{array}$ & $\begin{array}{l}\text { Solubilization } \\
\text { and } \\
\text { bioavailability }\end{array}$ & $\begin{array}{l}\text { Non-Steroidal Anti- } \\
\text { Inflammatory Drugs } \\
\text { such as Ketoprofen } \\
\text { Antiepileptic agents } \\
\text { such as Carbamazepine }\end{array}$ \\
\hline III & $\begin{array}{l}\text { High Solubility } \\
\text { Low } \\
\text { Permeability }\end{array}$ & $\begin{array}{l}\text { Enzymatic } \\
\text { degradation, gut } \\
\text { wall efflux, and } \\
\text { bioavailability }\end{array}$ & $\begin{array}{l}\text { Beta Blockers such as } \\
\text { Atenolol Histamine } 2 \\
\text { Receptor Antagonist } \\
\text { such as Ranitidine }\end{array}$ \\
\hline IV & $\begin{array}{l}\text { Low Solubility } \\
\text { Low } \\
\text { Permeability }\end{array}$ & $\begin{array}{l}\text { Solubilization, } \\
\text { enzymatic } \\
\text { degradation, gut } \\
\text { wall efflux, and } \\
\text { bioavailability }\end{array}$ & $\begin{array}{l}\text { Thiazide Diuretics such } \\
\text { as Hydrochlorothiazide } \\
\text { Loop Diuretics such as } \\
\text { Furosemide }\end{array}$ \\
\hline
\end{tabular}

illustrates some of the BCS classes I through IV drugs based on their solubility and permeability.

\section{Effects of particle size on solubility}

It is well known that particle size can greatly affect solubility. Thus various technologies have been used to enhance the solubility of a drug. Among these techniques for solubility enhancement and physical modifications of drug products, reducing the particle size and modifying crystal habit are the most common approaches to increasing drug solubility [22]. Particle technology, a technique used in pharmaceutics to modify physicochemical, micrometrics and biopharmaceutical properties of poorly soluble drugs, as a result, improving their solubility [22] (Figure 2).

Table 7 outlines some of the particle technologies that are used in pharmaceutics so as to reduce the particle sizes of solid substances thus increasing drug solubility. Also, examples of drugs that undergo the various processes are included [38,39].

\section{Chemical complexities}

Elemental composition: The elemental compositions of fine particles are very essential because they have an increased risk of causing harm especially if it is a pharmaceutical product. The possibilities of adverse reactions on individuals are particularly related to the elemental composition of drug particles composed of elements such as nickel $(\mathrm{Ni})$, zinc $(\mathrm{Zn})$, silicon $(\mathrm{Si})$, aluminum $(\mathrm{Al})$, vanadium $(\mathrm{V})$, chromium $(\mathrm{Cr})$, arsenic (As), and bromine $(\mathrm{Br})$ [41]. Some associated adverse effects of the elemental composition of a particle could cause the following: increased cardiovascular risk increased respiratory hospital admissions, increased mortality and lower birth weights. With these elemental compounds, it is reported that organic compounds as well as transition metals found in fine particles are known to have increased toxicity profiles as a result of them having the ability to cause inflammation alongside causing respiratory and cardiovascular effects [41,42].

Chemical form: The chemical form of fine particles is very important because it gives a genetic makeup of the fine particles just like the genetic makeup (DNA) in humans. Some chemicals found within fine particle include but are not limited to trace metals and some water-soluble ions. Some trace metals include: Iron $(\mathrm{Fe})$, Titanium $(\mathrm{Ti})$, and Manganese $(\mathrm{Mn})$. Some watersoluble ions include: Sodium $\left(\mathrm{Na}^{+}\right)$, Chloride $\left(\mathrm{Cl}^{-}\right)$, Magnesium $\left(\mathrm{Mg}^{2+}\right)$, Calcium $\left(\mathrm{Ca}^{2+}\right)$, Bromide $\left(\mathrm{Br}^{-}\right)$and Nitric Oxide $\left(\mathrm{NO}^{-}\right)$ [43].

Isotopic Ratios: These are indeed hazardous in fine particles because the particles are used by industries such as environment, mineral, and pharmaceutical. With these isotopes being unsafe

Table 7: Particle Technologies and Methods $[22,40]$

\begin{tabular}{|c|c|c|}
\hline $\begin{array}{c}\text { Particle } \\
\text { Technology }\end{array}$ & Methods & Examples \\
\hline $\begin{array}{l}\text { Mechanical } \\
\text { Micronization }\end{array}$ & $\begin{array}{l}\text { Jet Milling } \\
\text { Ball Milling } \\
\text { High Pressure } \\
\text { Homogenization } \\
(\mathrm{HPH})\end{array}$ & $\begin{array}{l}\text { Cilistazol, Ibuprofen, } \\
\text { Danazol, Carbamazepine, } \\
\text { Dypyridamole, } \\
\text { Indomethacin, Prednisolone, } \\
\text { Carbamazepine, Nifedipine }\end{array}$ \\
\hline $\begin{array}{l}\text { Particle Size } \\
\text { Reduction } \\
\text { by Novel } \\
\text { Particle } \\
\text { Engineering }\end{array}$ & $\begin{array}{l}\text { Cryogenic } \\
\text { Spraying, Process/ } \\
\text { Spray freezing } \\
\text { into liquid Crystal } \\
\text { Engineering }\end{array}$ & $\begin{array}{l}\text { Danazol,Carbamazepine, } \\
\text { Glibenclamide, Febantel, } \\
\text { Itraconazole }\end{array}$ \\
\hline $\begin{array}{l}\text { Solid SEDDS } \\
\text { Technology }\end{array}$ & $\begin{array}{l}\text { Spray Drying, in } \\
\text { situ salt formation, } \\
\text { solidification with } \\
\text { polymers }\end{array}$ & $\begin{array}{l}\text { Nimodipine, Flurbiprofen, } \\
\text { Dexibuprofen, Docetaxel, } \\
\text { Crucumin, Meloxicam, } \\
\text { Fenofibrate, Ibuprofen }\end{array}$ \\
\hline $\begin{array}{l}\text { Complexation } \\
\text { with } \\
\text { Cyclodextrins }\end{array}$ & $\begin{array}{l}\text { Freeze-drying, } \\
\text { vacuum } \\
\text { evaporation, kneading }\end{array}$ & $\begin{array}{l}\text { Praziquantel, Bifonazole, } \\
\text { Clotrimazole, Celecoxib }\end{array}$ \\
\hline $\begin{array}{l}\text { Polymeric } \\
\text { Micelles }\end{array}$ & $\begin{array}{l}\text { Dialysis, Freeze- } \\
\text { drying }\end{array}$ & $\begin{array}{l}\text { Paclitaxel, Etoposide, } \\
\text { Docetaxel, 17-AAG, } \\
\text { Amphotericin B }\end{array}$ \\
\hline $\begin{array}{l}\text { Freeze-dried } \\
\text { Liposomes }\end{array}$ & Freeze-drying & $\begin{array}{l}\text { Sirolomus (Rapamycin), } \\
\text { Paclitaxel }\end{array}$ \\
\hline $\begin{array}{l}\text { Solid Lipid } \\
\text { Nanoparticles }\end{array}$ & $\begin{array}{l}\text { HPH, Solvent } \\
\text { emulsification- } \\
\text { evaporation/diffusion }\end{array}$ & $\begin{array}{l}\text { All Trans-Retinoic Acid, } \\
\text { Tretinoin }\end{array}$ \\
\hline
\end{tabular}

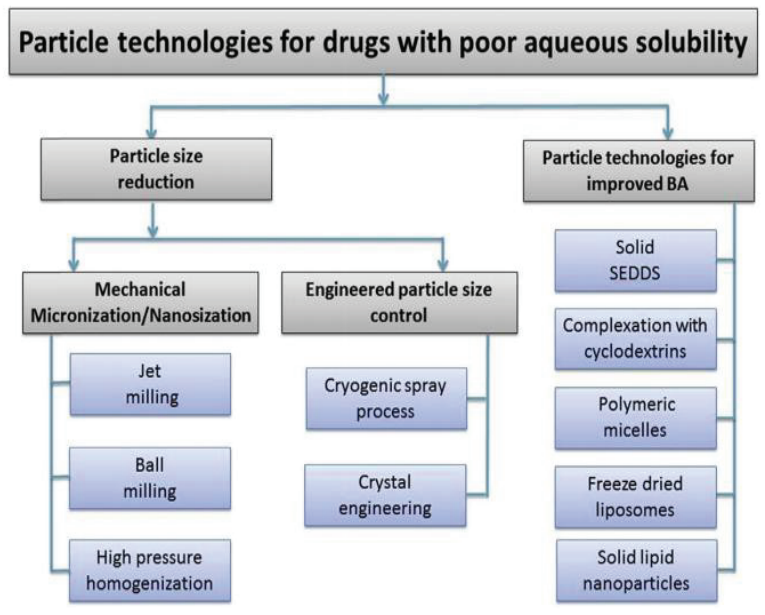

Figure 2: Particle Technology Sequence [22] 
to the general population, they tends to increase to toxicity of these fine particles.

An example would be mercury $(\mathrm{Hg})$ which is denoted as a globally distributed hazardous metal which is known for its environmental persistence and toxicity. Additionally, mercury has seven stable isotopes $\left({ }^{196} \mathrm{Hg},{ }^{198} \mathrm{Hg},{ }^{199} \mathrm{Hg},{ }^{200} \mathrm{Hg}\right.$, ${ }^{201} \mathrm{Hg},{ }^{202} \mathrm{Hg}$, and ${ }^{204} \mathrm{Hg}$ ) [44] and it being widely used in the population, leads to increase toxicity. Thus being cautiousness is required in using these hazardous isotopes in fine particles.

\section{Effects of fine particles}

The effects of fine particles have been excessively studied on health and how it affects respiratory conditions such as chronic obstructive pulmonary disease (COPD), asthma and pneumonia. These have led to increase mortality and hospital admissions or emergency room (ER) visits. Fine particles have been a greater health concern compared to coarse particles measuring at 10 micrometer, due to the fact that they have an increased chance of adverse effects. Additionally, these fine particles measured at 2.5 micrometer are mainly composed of many organic and inorganic compounds composed of nitrate, sulfate, carbonates, organic and elemental carbon, metals and water [45]. Moreover, the effects of fine particles have been demonstrated in cardiovascular diseases including ischemic heart disease, dysrhythmias, heart failure and cardiac arrest [46].

Respiratory health: It has been studied that the effects of fine particles on respiratory health predominantly occurs during the warm or cold seasons, but not both. It all depends on the region that is been studied. Per the article written by Cheng et al. [44], their studies indicated that the effects of fine particles were prime during the colder months. Conversely, the article written by Samoli et al. [45], demonstrated that fine particles do have an adverse effects on respiratory disease, but these occur mostly during the warmer months as opposed to the colder months. These particles are known to contain inhalable particles that are small enough thus making them to easily penetrate the thoracic region of the respiratory system [46,47].

Cardiovascular health: The effects of fine particles in cardiovascular diseases such as dysrhythmias, heart failure, ischemic heart disease, and cardiac arrest have led to increase mortality. This effect is due to long exposures between those with cardiovascular disease and fine particular matter [48]. Fine particles that affect cardiovascular diseases consist of transformational products such as sulfate and nitrite particles which are produced from primary sulfur and nitrogen oxide compounds as well as secondary organic aerosols from organic compounds [48]. Thus these fine particles are predicted to cause increased toxicities and pose an increased risk of systemic cardiovascular effects. Table 8 illustrates the relationship between particulate matter, particles size and its influence on human health.

\section{Statistical Analysis}

The goal of statistical analysis in particle size is to summarize a large amount of collected data into a form that could be useable and understandable while losing as little information
Table 8: Influences of Particulate Matter on Human Health [48]

\begin{tabular}{|l|c|l|}
\hline $\begin{array}{l}\text { Particulate } \\
\text { Matter (PM) }\end{array}$ & $\begin{array}{r}\text { Particle } \\
\text { Size }(\leq \mu \mathrm{m})\end{array}$ & \multicolumn{1}{|c|}{ Influence on Human Health } \\
\hline PM100 & 100 & $\begin{array}{l}\text { Persist in the air and no evidence of } \\
\text { adverse effects on human health }\end{array}$ \\
\hline PM10 & 10 & $\begin{array}{l}\text { Enter the respiratory system, deposit in } \\
\text { the respiratory tract and cause respiratory } \\
\text { diseases }\end{array}$ \\
\hline PM2.5 & 2.5 & $\begin{array}{l}\text { Get into the alveoli through the respiratory } \\
\text { tract and then enter into the blood } \\
\text { circulation, causing various diseases. }\end{array}$ \\
\hline PM0.1 & 0.1 & \multicolumn{2}{|c|}{} \\
\hline
\end{tabular}

as possible about the original population. Moreover, the use of statistical analysis for heterogeneous systems, such as those with a PSD is often needed. Some areas where statistical understanding is necessary includes: sampling, display of information (discontinuous and continuous distributions, number and volume/mass, statistical process control, and calculations and understanding averages).

Furthermore, a prime example of a continuous distribution is illustrated with a frequency curve, which easily passes through any point in a histogram bar. With this in mind, an infinitely small increment in size, indicates an infinitely small quantity in the vertical axis. In this instance, the horizontal and vertical axis presents a mathematical challenge with any particle size technique. A linear vertical axis can't deal with small numbers of particles while a horizontal linear axis can't deal with the ranges typically encountered in particle size analysis.

In order for the continuous distribution to be properly represented on the vertical axis, it has to have the same number of horizontal bands, having a correct understanding of the meaning of the axis such as understanding the nature of the measurement and understanding the lower end mathematical "brick wall". Finally, applying appropriate transformations which results in understanding any assumptions and applicability. The calculation of minimum mass was depicted using two different approaches by Pierre Gy and A. F. Rawle. Pitard/Gy used $\sigma^{2}$ while Rawle used numbers of particles.

$$
\begin{aligned}
& \text { Pitard/Gy: } \\
& M s=18 p f d^{3} / \sigma^{2}
\end{aligned}
$$

(Where $\mathrm{d}$ refers to $95 \%$ passing)

$\mathrm{F}=$ shape factor $(=\pi / 6$ for spheres, 1 for cubes $)$

Rawle:

$$
M s=p(\pi / 6) d^{3} / \sigma^{2}
$$

(For X95; spheres considered)

$\mathrm{p}$ is denoted as the density in $\mathrm{g} / \mathrm{cm} 3, \mathrm{~d}$ is denoted as the size in $\mathrm{cm}$, and $\sigma$ is denoted as the fundamental sampling error (FSE) (Pitard/Gy). Gy sampled some theory error types for particulate materials and they are represented alongside their description in the Table 9 below: 
Table 9: Theory Error Types for Particulate Materials

\begin{tabular}{|l|l|l|}
\hline Notation & \multicolumn{1}{|c|}{ Error Type } & \multicolumn{1}{|c|}{ Subject/Description } \\
\hline FE & $\begin{array}{l}\text { Fundamental } \\
\text { Error }\end{array}$ & $\begin{array}{l}\text { A result of the constitutional } \\
\text { heterogeneity, CH (the particles being } \\
\text { chemically or physically different) }\end{array}$ \\
\hline CE2 & $\begin{array}{l}\text { Grouping and } \\
\text { Segregation } \\
\text { Error }\end{array}$ & $\begin{array}{l}\text { Aong-Range } \\
\text { Aeterogeneity } \\
\text { heterogeneity, DH }\end{array}$ \\
\hline FE3 & $\begin{array}{l}\text { Periodic } \\
\text { Heterogeneity } \\
\text { Fluctuation Error }\end{array}$ & $\begin{array}{l}\text { Trends across space or over time } \\
\text { time }\end{array}$ \\
\hline DE & $\begin{array}{l}\text { Increment } \\
\text { Delimitation Error }\end{array}$ & $\begin{array}{l}\text { Identifying the correct sample to take. } \\
\text { Considers the volume boundaries of a } \\
\text { correct sampling device }\end{array}$ \\
\hline EE & $\begin{array}{l}\text { Increment } \\
\text { Extraction Error }\end{array}$ & $\begin{array}{l}\text { Removing the intended sample. } \\
\text { Considers the shape of the sampling } \\
\text { device cutting edges }\end{array}$ \\
\hline PE & $\begin{array}{l}\text { Preparation Error } \\
\text { Sample degradation, gross errors, } \\
\text { analyte loss or gain }\end{array}$ \\
\hline
\end{tabular}

Statistical tests are divided into two groups: parametric tests and nonparametric tests [49]. These are further discussed in the paragraphs below and they each demonstrate examples that are commonly used today. Some of these statistical tests are used in analyzing the pharmacologic properties of APIs.

\section{Parametric tests}

These are often more robust and require less data to make a stronger conclusion. This test requires at least three parameters of the data to be true as opposed to assumed. First parameterthe data is required to be normally distributed meaning it must follow a bell-shaped curve. Secondly, the data needs to have an equal variance and standard deviation. Finally, the data must be continuous. Examples include: Pearson product correlation coefficient, student t-test, z-test and ANOVA (analysis of variance) test. The Pearson product correlation coefficient is denoted as (r) and indicated how well two continuous variables from the same subject correlate with each other. Additionally, the student t-test regarded as the most widely used test due to its involvement of the mean, standard deviation and number of samples to calculate test statistics. Moreover, the $\mathrm{z}$-test uses the variance of the standard population as opposed to the standard deviation and finally, the ANOVA (analysis of variance) test incorporates both the mean and variances in order to determine the test statistic. Also, it is used to indicate if the groups are the same or different and the null hypothesis is often stated as the groups are the same and its statistic test is called the F-ratio.

\section{Nonparametric test}

If the data does not meet any of the parameters for the parametric test listed above, then it must be analyzed using the nonparametric tests. With the nonparametric tests, more data is often required to make the same conclusion. As such, data that is presented in a categorical manner often have to be converted to a continuous data before being analyzed. Some examples include: chi-square, spearman rank coefficient, mann-whitney u-test, and kruskal-Wallis. The chi-square test is used to compare multiple groups where the input and output variables are binary, while the spearman rank coefficient unlike the pearson product correlation coefficient, determines how well two variables for individual data points predict each other. Furthermore, the mann-whitney u-test, sometimes referred to as the Wilcoxson rank test is analogous to the t-test for continuous variables and can also be used for ordinal data. It compares two independent populations to determine if they are truly different. Finally, the Kruskal-Wallis test uses the ranks for ordinal data to perform an analysis of variance in order to determine whether multiple groups are similar to each other or not.

\section{Criteria for Validation of Test}

The main goal of validation of an analytical test is to demonstrate that the method is suitable for its intended use, such as evaluation of a known product for potency and impurities. Also, the intent of test validation is to provide scientific evidence that the analytical method is reliable and consistent before it can be used in routine analysis of product. The key criteria for evaluation of an analytical method include: specificity, accuracy, precision, detection limit, quantitation limit, sensitivity, working range and linearity, robustness, and reproducibility. This validation method is governed by the ICH [50]. Table 10 elaborates on the definitions for each on the validation characteristics as described by $\mathrm{ICH}$.

\section{Summary}

This review summaries the most recent advances in fine particle characterization from different views of direct and indirect analytical methods. These two methods of characterization assist in the recognition of the various inclusions of identifying fine particles. With specifics on pharmaceutical drug formulations; the information gathered in this review, serves as a comprehensive data collection for all working on formulation. Moreover, the use of statistical analysis is well explained here and includes some of the formulas used by known statisticians in summarizing large amounts of collected data into a form that could not just be understandable, but also useable without losing data from the original populations. There are various areas within drug formulation where there is a need for statistical understanding. This includes but not limited to sampling, display of information involving discontinuous and continuous distributions, number and volume/mass, statistical process control and calculation averages.

Furthermore, particle characterization is always based on the measurements of the particle size (PS), particle size distribution (PSD), sometimes particle shape, and morphology. On the same note, PSD affects properties of fine particles such as suspension. The PSDs of drug substances and excipients both affect drug product manufacturability involving flow ability, 
Table 10: Criteria for Test Validation and Definitions [50]

\section{Validation}

Characteristics

ICH Definitions

\begin{tabular}{|c|c|}
\hline Specificity & $\begin{array}{l}\text { Ability to assess unequivocally the analyte in the presence of components which } \\
\text { may be expected to be present such as impurities, degradants matrix, etc. }\end{array}$ \\
\hline Accuracy & $\begin{array}{l}\text { Also known as trueness. It expresses the closeness of agreement between the value that is accepted either as a conventional } \\
\text { true value or an accepted reference value and the value found. }\end{array}$ \\
\hline Precision & $\begin{array}{l}\text { Expresses the closeness of agreement (degree of scatter) between a series of measurements obtained from multiple } \\
\text { sampling of the same homogenous sample under the prescribed conditions. Typically categorized in three levels: repeatability, } \\
\text { intermediate precision and reproducibility. }\end{array}$ \\
\hline Repeatability & This expresses the precision under the same operating conditions over a short interval of time. \\
\hline Reproductively & This expresses the precision between laboratories (collaborative studies usually applied to standardization of methodology). \\
\hline Detection Limit & This is the lowest amount of analyte in a sample that can be detected but not necessarily quantitated as an exact value. \\
\hline Quantitation Limit & This is the lowest amount of analyte in a sample that can be quantitatively determined with suitable precision and accuracy. \\
\hline Linearity & $\begin{array}{l}\text { It is the ability (within a given range) to obtain test results that are directly proportional to the concentration (amount) of analyte } \\
\text { in the sample. }\end{array}$ \\
\hline Working Range & $\begin{array}{l}\text { This is the interval between the upper and lower concentration (amounts) of analyte in the sample (including these concentrations) } \\
\text { for which it has been demonstrated that the analytical procedure has a suitable level of precision, accuracy, and linearity. }\end{array}$ \\
\hline Robustness & $\begin{array}{l}\text { This is a measure of its capacity to remain unaffected by small, but deliberate, variations in method parameters and also } \\
\text { provides an indication of its reliability during normal usage. }\end{array}$ \\
\hline
\end{tabular}

blend uniformity, compatibility, which in turn can affect the safety, efficacy, and quality of specific drug products. Therefore, understanding the impact of particle size and shape of powders on manufacturing processes is critical. Finally, knowing the importance of PS and PSD of fine particles is very important to the overall composition of the entire compound and its characteristics.

\section{Acknowledgement}

This work was supported by the University System of MarylandUSM-(Wilson H. Elkins Professorship Award 2016). The authors are also grateful to U.S. Food and Drug Administration, and Coppin State University for their administrative support. The content is exclusively the responsibility of the authors and does not necessarily represent the official views of the funding agencies.

\section{References}

1. Weichenthal SA, Lavigne E, Evans GJ, Godri Pollitt KJ, Burnett RT, et al. (2016) Fine Particulate Matter and Emergency Room Visits for Respiratory Illness: Effect Modification by Oxidative Potential. Am J Respir Crit Care Med 194: 577-586.

2. Pei $Y$, Jiang R, Zou $Y$, Wang $Y$, Zhang S, et al. (2016) Effects of Fine Particulate Matter (PM2.5) on Systemic Oxidative Stress and Cardiac Function in ApoE(-/-) Mice. Int J Environ Res Public Health 12: E484.

3. Barbosa-Canovas GV, Harte F, Yan HH (1997) Particle Size Distribution in Food Powders. Food Eng 1: 2-4.

4. Fairhurst, D. and Weiner, B. A Guide to Determination of Particle Size - Making an Effective and Reliable Measurement. Brookhaven instruments 1-2.

5. Su T, Chen T, Zhang Y, Hu P (2016) Selective Flocculation Enhanced Magnetic Separation of Ultrafine Disseminated Magnetite Ores. Minerals. 2016 6: 86.

6. Prakash Khadkaa, Jieun Roa, Hyeongmin Kim, Iksoo Kima, Jeong Tae Kim, et al. (2014) Pharmaceutical particle technologies: An approach to improve drug solubility, dissolution and bioavailability. Asian J Pharm Sci 9: 304-316.
7. Dueck GJ, Kilimnik YD, Min'kov LL, Neesse T (2003) Measurement of the Rate of Sedimentation of Fine Particles in a Platelike Centrifuge. J Eng Phys Thermophys 76: 748-749.

8. Ommen VR (2008) Sedimentation. Introduction to Particle Technology 2: 4-5.

9. Brittain GH (2002) Particle Size Distribution, Part III: Determination by Analytical Sieving. Pharmaceutical Technology 56-57.

10. Cruz DJ (2016) Basic Quantitative Microscopy: Practical Pitfalls in Imaging Acquisition. Cornell University Institute of Biotechnology 1-41.

11. Baumann B (2017) Polarization Sensitive Optical Coherence Tomography: A Review of Technology and Applications. Appl Sci 7: 474 .

12. Ding H, Popescu G (2010) Instantaneous Spatial Light Interference Microscopy. Optical Society of merica. 18: 1569-1575.

13. Kim M, Choi Y, Fang-Yen C, Sung Y, Kim K, et al. (2012) ThreeDimensional Differential Interference Contrast Microscope Using Synthetic Aperture Imaging. J Biomed Opt 17.

14. Storti F, Balsamo F (2010) Particle size distributions by laser diffraction: sensitivity of granular matter strength to analytical operating procedures. Solid Earth 1: 25-26.

15. Ayan C, Hafez H, Hurst S, Kuchuk F, O'Callaghan A, et al. (2001) Characterizing Permeability with Formation Testers. Autumn 3.

16. Faizova AN, Raab GI, Faizov IA, Aksenov DA., Zaripov NG, et al. (2016) The Effects of the Second Phase Particles Size on Fracture Behavior of Cu-0.1\% Sn Ultra-Fine-Grained Alloy. Russian Physics Journal 59: 1.

17. Yang RY, Zou RP, Yu AB, Choi SK (2006) Pore Structure of the Packing of the Fine Particles. Journal of Colloid and Interface Science 299: 719-725.

18. Reynolds AR., Stramski D, Wright MV, Woźniak BS (2010) Measurements and Characterization of Particle Size Distribution in Coastal Waters. J Geophys Res 115: 1-19. 
19. Lui Y, Xia B, Du B, Farzaneh M (2016) Influence of Fine Metal Particles on Surface Discharge Characteristics or Outdoor Insulators. Energies 87: 2-3.

20. Sarofim AF, Lighty JS, Eddings EG (2002) Fine Particles: Health Effects, Characterization, Mechanisms of Formation and Modeling. Fuel Chemistry Division Preprints 47: 618-620.

21. Malvern Instruments Limited (2015) A Basic Guide to Particle Characterization. Precision Instrumentation and Control Company 2-4.

22. Khadka P, Ro J, Kim H, Kim I., Kim TJ, et al. (2014) Pharmaceutical Particle Technologies: An Approach to Improve Drug Solubility, Dissolution and Bioavailability. Asian J Pharm Sci 9: 304-316.

23. Argade PS, Magar DD, Saudagar RB (2013) Solid dispersion: Solubility enhancement technique for poorly water soluble drugs. J Adv Pharm Technol Res 3: 427-439.

24. Kumar BT, Nagaraju K, Eswaraiah CM (2012) An overview enhancement of solubility and dissolution rate. Int Res J Pharm Appl Sci 2: 198-210.

25. Kalepu S, Nekkanti V (2015) Insoluble Drug Delivery Strategies: Review of Recent Advances and Business Prospects. Acta Pharmaceutica Sinica B 5: 442-453.

26. Dizaj SM, VazifehasI Z, Salatin S, Adibkia K, Javadzadeh Y (2015) Nanosizing of drugs: Effect on dissolution rate. Res Pharm Sci 10: 95-108.

27. Junyaprasert BV, Morakul B (2015) Nanocrystals for Enhancement of Orla Bioavailability of Poorly Water-Soluble Drugs. Asian J Pharm Sci 10: 13-23.

28. U.S Pharmacopeia Convention (2011) U.S Pharmacopeia National Formulary. United States Pharmacopeia.

29. Groover PM (2010) Fundamentals of Modern Manufacturing: Materials, Processes and Systems. In: John Wiley \& Sons Publication 4th Edition: 348.

30. Hoag S, Lim H (2008) Paticle and Powder Bed Properties. Taylor \& Francis Group. $3^{\text {rd }}$ Edition 31: 17-73.

31. Alexander MJ, Bell MD, Imre D, Klieber DP, Grassian HV, et al. (2016) Measurement of Size-Dependent Dynamic Shape Factors of Quartz Particle in Two Flow Regimes. Aerosol Sci Tech 50: 870-879.

32. Bartos C, Szabo-Revesz P, Bartos C, Katona G, Jojart-Laczkovich O, et al. (2016) The Effect of an Optimized Wet Milling Technology on the Crystallinity, Morphology and Dissolution Properties of Micro- and Nanonized Meloxicam. Molecules 21: 507.

33. Kumar S, Singh P (2016) Various Techniques for Solubility Enhancement: An Overview. The Pharma Innovation Journal 15: 23-28.

34. Wen H, Jung H, Li X (2015) Drug Delivery Approaches in Addressing Clinical Pharmacology-Related Issues: Opportunities and Challenges. AAPSJ 17: 1327-1340.

35. Patil MS, Godse SG, Saudagar RB (2013) Solubility Enhancement by Various Techniques: An Overview. WJPPS. 2013 2: 4558-4572.
36. Godse SZ, Patil MS, Kothavade SM, Saudagar RB (2013) Techniques for Solubility Enhancement of Hydrophobic Drugs: A Review. J Adv Pharm Edu Res 3: 403-414.

37. Kansara H, Panola R, Mishra A (2015) Techniques Used to Enhance Bioavailability of BCS Class II Drugs: A Review. Int J Drug Dev Res 7: 82-93.

38. Morakinyo OM, Mokgobu MI, Mukhola MS, Hunter RP (2016) Health Outcomes of Exposure to Biological and Chemical Components of Inhalable and Respirable Particulate Matter. Int J Environ Res Public Health 13: 592.

39. Savjani TK, Gajjar KA, Savjani KJ (2012) Drug Solubility: Importance and Enhancement Techniques. ISRN Pharm 1: 1-10.

40. Vimalson CD, Parimalakrishnan S, Jeganathan SN, Anbazhagan $S$ (2016) Techniques to Enhancing Solubility of Hydrophobic Drugs: An Overview. Asian J Pharm 10: 67-75.

41. Koulouri E, Saarikoski S, Theodosi C, Markaki Z, Gerasopoulos E, et al. (2008) Chemical Composition and Sources of Fine and Coarse Aerosol Particles in the Eastern Mediterranean. Atmos Environ 42: 6542-6550.

42. Huang $Q$, Chen J, Huang W, Fu P, Guinot B, et al. (2016) Isotopic Composition for Source Identification of Mercury in Atmospheric Fine Particles. Atmos Chem Phys 16: 11773-11786.

43. Cheng M, Chiu H, Yang C (2015) Coarse Particulate Air Pollution Associated with Increased Risk of Hospital Admissions for Respiratory Disease in a Tropical City, Kaohsiuug, Taiwan. Int J Environ Res Public Health 12: 13053-13068.

44. Samoli E, Stafoggia M, Rodopoulou S, Ostro B, Declercq C, et al. (2013) Associations between Fine and Coarse Particles and Mortality in Mediterranean Cities: Results from the MEDPARTICLES Project. Environ Health Perspect 121: 932-938.

45. World Health Organization (2013) Health effects of Particulate Matter. Joint WHO/Convention Task Force on Health Aspects of Air Pollution 6-20.

46. Ostro B, Roth L, Malig B, Marty M (2009) The Effects of Fine Particle Components on Respiratory Hospital Admissions in Children. Environ Health Perspect 113: 475-480.

47. Pope CA, Dockery WD (2006) Health Effects of Fine Particulate Air Pollution: Lines that Connect. J Air Waste Manage Assoc 56: 709-742.

48. Wang C, Tu Y, Yu Z, Lu R (2015) PM2.5 and Cardiovascular Disease in the Elderly: An Overview. Int J Environ Res Public Health 12: 8187-8197.

49. Neideen T, Brasel K (2007) Understanding Statistical Tests. J Surg Educ 64: 93-96.

50. Belouafa A, Habti F, Benhar S, Belafkih B, Hamdouch S, et al. (2017) Statictical Tools and Approaches to Validate Analytical Methods: Methodology and Practical Examples. Int J Metrol Qual Eng 8: 1-10. 